\title{
The Technology of the Development of Dialogical Speech Skills of the Students Based on Foreign Language Communicative Online Training
}

\author{
Galina Sorokoumova ${ }^{1, *}$, Ekaterina Tataurova ${ }^{1}$, Tatiana Egorova ${ }^{2}$, Olga Kostina $^{2}$, and Olga \\ Fedoseeva $^{3}$ \\ ${ }^{1}$ Linguistics University of Nizhny Novgorod, 603155 Nizhny Novgorod, Russia \\ ${ }^{2}$ Nizhny Novgorod Institute of Management - a branch of Russian Presidential Academy of National \\ Economy and Public Administration 603057 Nizhny Novgorod, Russia \\ ${ }^{3}$ Nizhny Novgorod State Academy of Ministry of Internal Affairs, 603950 Nizhny Novgorod, Russia
}

\begin{abstract}
The topic of the article is quite acute as there exists a need to search for new online educational technologies that will further increase the efficiency of foreign language educational process at modern universities in Russia. The purpose of the article is to present the methodological foundations of foreign language communicative preparation and analyze the quality of the influence of foreign language communicative online training on the development of dialogical speech skills of the students. The leading method of studying this issue is an experimental teaching method. The study was carried out among bachelor's degree students majoring in 44.03.01 «Pedagogical education» with a minor of «English as a foreign language» at Linguistics University of Nizhny Novgorod, Russia and allowed to reveal the positive dynamics in the experimental groups. The article proves that foreign language communicative online training is a modern educational technology that aims at active development of students' dialogical speech skills and significantly differs from ordinary communicative training in the following features: the presence of certain stages correlated with the developed dialogical speech skills of students, ensuring active social preparation of students to further implementation of foreign language communication in the field of interpersonal and professional interaction; creation of conditions for expanding individual foreign language communicative experience. The materials presented in the article contribute to the integration of the procedural component of foreign language communicative online training in foreign language classes at the university.
\end{abstract}

\section{Introduction}

A modern Russian University is a social institution that should create necessary educational conditions for the development of a harmonious socially interactive person. This goal

${ }^{*}$ Corresponding author: galsors@mail.ru 
may be achieved at Foreign language classes, where a tutor will be able to create a special educational environment that will contribute to personal communicative development of every student. To realize this idea a tutor must be in a permanent search of new methods of training and education, educational technologies that ensure the development of basic skills and abilities of students, increasing their motivation to learn and involvement in the educational process.

This problem of searching for new educational technologies is relevant both for Russian and foreign researchers. For example, M. N. Norbahira and A. R. Radzuwan consider three main theoretical aspects of learning and mastering the first and second languages and suggest several original educational technologies for their development [10]. M. Bolognesi and P. Vernillo research the role of metonymy in the representation of abstract concepts in the analysis of verbal and visual metaphors of the language. Such deep analysis helps students to go deeper into the understanding of underneath meanings and hidden context in the dialogue with a native speaker [1]. S. Leher \& K. S. See study different methods of language learning based on the proportion of quantity and quality of language material presented [7].

However, COVID-19 Global pandemic deprived all educational institutions of a chance to conduct offline classes. Present-day reality motivates us to re-examine all the modern educational technologies from the point of their successful integration into online teaching and learning process.

One of such technologies that became widely used in Russian educational space that was greatly modified by SARS-CoV-2 infection is communicative training technology. This type of technology «grew up» from psychological training and is an effective form of developing of communicative skills [13].

The analysis of modern Russian research literature dedicated to the problems of the usage of communicative training technology in higher education indicates a constant increase of scientific interest of this problem [12]. However, almost no research papers in this area concentrates on studying its impact on foreign language education [14]. Most of the researchers consider communicative training to be a form of synthesis of various methods and techniques for providing theoretical and practical communicative training of students within their native society [4]. The question of using the technology of communicative training for the development of foreign-language dialogic skills is studied rather insufficiently. Thus, the purpose of our research is to study and test foreign language communicative training as a separate specific educational technology that accelerates the development of dialogical speech skills of bachelor's degree students majoring in 44.03.01 «Pedagogical education» with a minor of «English as a foreign language» at Linguistics University of Nizhny Novgorod, Russia.

In our research we define foreign language communicative training as a modern educational technology that aims at active development of foreign language dialogic speech skills in the process of intensive interpersonal online interaction. This special type of training is aimed at developing communicative competence as the ability to establish and maintain social contacts, resolve conflict situations that arise in the process of communication, as well as to select various means of communication according to the goals and conditions of communication. Unlike classical training foreign language communicative training aims at developing the components of foreign language communicative competence of student's skills of dialogical speech, and modeled with rules, regulations, policies of social and communicative behavior of foreign society.

To add to this, as a kind of pedagogical technology, a foreign language communicative training has several characteristics common to this pedagogical category, among which are the following: conceptuality, consistency, manageability, efficiency, reproducibility. It is important for us to mention these characteristics as they also let this technology to be effective in online learning process [11].

Let us look at some of them in more detail. 
- Conceptuality.

Modern researchers classify training technologies as a part of «action learning» method («learning through action», «learning by meaningful action»), the founder of which is R. Revans [6].

Learning through action is generally performed using The Revans-Marquardt's formula, which looks like this:

$\mathrm{L}=\mathrm{P}+\mathrm{Q}+\mathrm{R} \quad(1)$

where L - stands for learning, P - stands for programmed knowledge, Q - stands for asking a question to create insight, and $\mathrm{R}$ - stands for reflection [2].

2. Consistency.

This quality of foreign language communicative training is manifested in the presence of an invariant system of principles necessary for creating an effective educational environment.

3. Manageability.

This characteristic is universal for pedagogical technology and assumes «the possibility of diagnostic goal-setting, planning, designing the learning process, step-by-step diagnostics, varying tools and methods to correct the results» [9].

These characteristics are also realized through its format, that presupposes the existence of six following stages: 1) introduction; 2) initial analysis of the communicative situation; 3) search for the new effective ways of communicative interaction; 4) development of communicative abilities at the micro-level; 5) development of communicative abilities at the macrolevel; 6) reflection.

4. Reproducibility.

The availability to transfer the technology of foreign language communicative training to any other university educational program is explained by its clear, understandable, and effective structure. In general, the composition of any training involves three basic parts: the introductory part, the main part, and the final part. The basis for building many modern trainings is learning cycles, which effectiveness has been repeatedly confirmed in the scientific works of foreign and domestic researchers [8].

The content of the technology of foreign language communicative training presupposes the implementation of special types of tasks that were developed based on psychological and pedagogical features of modern university students and include set of personally significant topics and situations. The developed types of exercises include the following: 1) communicative-stimulating; 2) communicative-analytical; 3) communicative-constructing; 4) communicative-fixing; 5) communicative-developing; 6) communicative-reflexive.

Since we believe that foreign language communicative training has a very high potential for online foreign language learning and acquisition, let us briefly characterize the main difference between online and offline communication. Virtual communication differs significantly from real one and has the following unique characteristics: 1) high degree of efficiency; 2) anonymous nature of communication; 3 ) absence of stress factors of the real socializing environment.

Let us consider these features in more detail.

1. High degree of efficiency.

The development of various social networks and instant messaging services (Vk.com, Facebook, WhatsApp, Viber, etc.) has led to the blurring of space-time boundaries between communicants. As a result, the communicative space of the interlocutors becomes autonomous, which allows them not to depend on time, as an online resource is available 24 hours a day. At the same time, the replicas in the dialogical unity of Internet communication are not ordered. The course of the conversation can be disrupted in the course of a technical failure of the Internet or if the addressee misses some questions of his interlocutor. Thus, 
although the dialogue in the network «preserves the chronology, but this chronology records only the moment of sending and does not reflect the logical sequence of elements of communication» [15].

2. Anonymous nature of communication.

The lack of personal contact between the interlocutors and the restriction in the use of verbal means of communication on the Internet create conditions for distorting the process of network communication. Computer-mediated communication allows the Internet user to self-model their personality. To do this, they can use a pseudonym instead of a real name or post information that does not correspond to reality, which leads to erosion of the real identity of the communicants. Moreover, in conditions of virtual communication with a minimum of data about the communication partner, the interlocutor independently creates his image for himself, trying to simultaneously imagine how his words are perceived in a joint dialogue. Thus, the real addressee is absent and can only be «completed» in the sender's mind on the basis of his personal social and communicative experience.

3. Absence of stress factors of a real socializing environment.

In the process of interacting with society, a person experiences a certain level of social pressure in the form of special norms of behavior, certain rules, and principles of interpersonal interaction, approved by this society. Some of them may conflict with their needs. To achieve a balance between these two processes, society offers a person a set of ready-made statuses and roles that he can realize during his life. According to the theory of roles, one of the characteristics of a formed personality is its belonging to certain types of social roles inherent in each society. The virtual space, represented by the Internet and perceived by a person as «not real», does not carry any social danger in its content. However, such freedom of expression of can grow into impunity. Using this, any user can falsify information and «slander other people or organizations or insult and humiliate without fear of responsibility for their behavior» [3].

\section{Materials and Methods}

Practical research was carried out and objectively assessed in the course of a training experiment on the basis of Linguistics University of Nizhny Novgorod, Russia in the framework of the main educational program 44.03.01 «Pedagogical education» with a minor of «English as a foreign language».

The organization of the pilot test was carried out in the academic year 2019-2020. The total number of participants was 60 people. This article provides data for two groups, each of which consisted of 12 people.

To maintain the consistency and clarity of the experiment, we designated one of them as group No. 1 - the experimental group (hereinafter referred to as the EG), and the second was designated as group No. 2 - the control group (hereinafter referred to as the CG).

The number of non-variable conditions of the experiment included: the same amount of time allotted for the assimilation of educational material; duration of classes (90 minutes); regularity of the lessons (3 lessons 3 times per week) the number of subjects in the EG and the CG; approximately the same starting level of development of universal competencies in the EG and CG at the moment of the beginning of experimental training; the content of the ascertaining and final diagnostics; uniform assessment criteria; a unified form of processing statistical data of the experiment.

The number of variable conditions of the experiment included: different teachers teaching in the EG and CG; leading teaching technology; the form of organizing and conducting classes.

We tried to evaluate student's dialogical speech performance twice: first before the experimental learning and second after the experiment. For the most effective assessment of the 
initial and final indicators that allow you to clearly track the dynamics of the development of certain foreign language skills of dialogic speech, a special system of criteria was developed, based on the theory of three sides of communication, highlighted by G. M. Andreeva [5].

The communicative side of dialogical communication assumed an assessment of the level of development of foreign language skills of dialogical speech of high school students using the following quantitative criteria: 1) the number of replicas from each interlocutor; 2) the number of different types of dialogical units; 3 ) the number of hesitation pauses. Qualitative indicators of the level of development of foreign language skills of dialogical speech of high school students in the framework of the communicative side of dialogical communication were evaluated using the following qualitative criteria: 1) compliance of the contents of the dialogic utterance set of communicative tasks; 2) lexico-grammatical and phonetic correctness of the utterances; 3 ) pragmatism and emotion in building a dialogical statement.

The perceptual side of dialogical communication was supposed to assess the level of development of foreign language skills of dialogical speech of high school students using the following quantitative criteria: 1) the amount of time spent actively listening to the interlocutor; 2) the number of clarifying questions asked to the interlocutor; 3 ) the number of replicas that express the speaker's attitude to the interlocutor's statement. Qualitative indicators of the level of development of foreign language skills of dialogical speech of high school students in the framework of the perceptual side of dialogical communication were measured using the following criteria: 1) perception and interpretation of information about verbal signals from the communication partner received during the dialogue; 2) ability to act in various roles; 3 ) ability to predict possible reactions of the partner in the process of communication.

The interactive side of dialogical communication was supposed to assess the level of development of foreign language skills of dialogical speech of high school students using the following quantitative criteria: 1) the number of replicas aimed at maintaining dialogical unity on the part of each interlocutor; 2) the number of specific speech tools (conversational formulas, clichés, formulas of speech etiquette) used in the dialogue by each of the interlocutors; 3 ) the number of arguments given in the process of dialogical communication by each of the interlocutors. Qualitative indicators of the level of development of foreign language skills of dialogical speech of high school students within the interactive side of dialogical communication were measured using the following criteria: 1) flexibility in the development of the topic and subject of communication; 2) the use of cooperation strategies in the dialogue; 3) the ability to predict possible conflicts and resolve them.

\section{Results}

After the completion of the learning experiment, we evaluated both qualitative and quantitative indicators of the progress in EG and CG. For the most effective assessment of the initial and final indicators of the development of foreign language dialogical speech skills, a special system of criteria has been developed. Verbal answers of the students were studied and evaluated according to 3 quantitative and 3 qualitative criteria for each of communication units that were previously mentioned. According to the primary data, we calculated the overall average score of the qualitative and quantitative indicators in the EG and CG before the experiment. Then we evaluated the success rate of the performance of students both in EG and $\mathrm{CG}$, according to the formula of Bespalko:

$$
K y=a / n,
$$

Where «a» stands for the number of students who showed a generally positive result and «n» is a total number of students in the group. 
The results for both groups before learning experiment was 0.5 with an average acceptable score of 0.7 , which indicates an extremely low level of the development of the foreign language speech skills within the groups. After the learning experiment we also calculated the overall average score of the qualitative and quantitative indicators in the EG and CG and then evaluated the success rate of the performance of the students in the EG and CG, according to the formula of Bespalko. The results for the CG was 0.583 whereas the result of the EG was 1.0 withan average acceptable score of 0.7 , which indicates a high level of the development of foreign language dialogical speech skills in EG and low average in CG. A comparative analysis of the data of ascertaining and final periods demonstrates an intensive positive dynamic change among qualitative and quantitative indicators of the level of the development of dialogical speech skills in foreign language in the EG. (see Fig. 1).

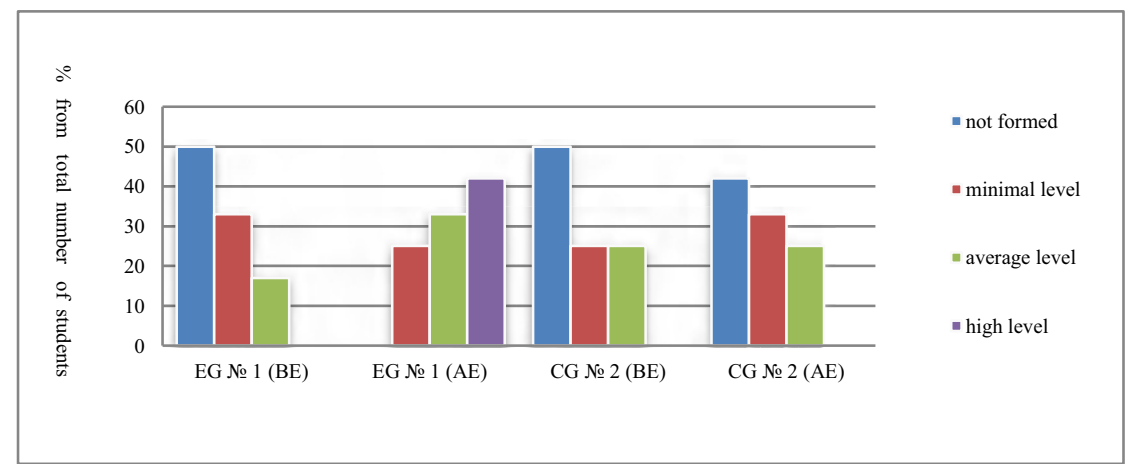

Fig. 1. The level of development of dialogical speech skills in the EG and CG before experimental learning $(\mathrm{BE})$ and after experimental learning (AE).

The obtained data allow us to draw a conclusion about the intensive positive dynamics of changes in qualitative and quantitative indicators of the level of development of foreign language dialogic speech skills in the EG based on the results of the learning experiment.

In the EG several students with high level of the foreign language communicative competence development increased up to $42 \%$. The number of students with an average level increased to $33 \%$. The number of students with the minimum level decreased up to $25 \%$. Students in the CG did not show such significant results as students in the EG. The number of students with the minimum level increased to $33 \%$, however, the number of students with an average level stayed the same, while the number of students with a high level of performance remained at zero.

Thus, a comparative analysis of the results of the ascertaining and control stages of the study confirms the effectiveness of the foreign language communicative online training created by us for the development of dialogical speech skills of university students.

\section{Discussion}

The relevance of the development of foreign language dialogic speech skills within the university is determined not only by the requirements of the Federal Educational Standard for the professional results of gathering the bachelor's degree in program 44.03 .01 «Pedagogical education» with a minor of «English as a foreign language», but also by the indicators of the level of development of the personal characteristics of the graduate - the future teacher of a foreign language, who must be able to conduct a constructive conversation with any interlocutor and always achieve mutual understanding in the process of communication. 
Based on these requirements, the orientation of the process of foreign language education to the simultaneous development of students' skills in communicative, interactive, and perceptual aspects of dialogical speech in a foreign language is of particular importance.

To achieve this goal, the list of skills required for development in foreign language classes at the university was clarified in accordance with the three sides of dialogical communication: the communicative side of dialogical communication (the ability to establish contact, the ability to achieve the set communication goal, the ability to argue your point of view); the perceptual side of dialogical communication (the ability to actively listen to a partner; the ability to understand and accept the point of view of the interlocutor; the ability to assess and predict the verbal behavior of the partner; the interactive side of dialogical communication (the ability to navigate in a communication situation, the ability to assess the effectiveness of one's own communicative behavior, the ability to communicate in conflict situations).

Modern students are representatives of generations «Z» and «Alpha». The emerging information society had a significant impact on the processes of their personal formation and development. Under the influence of high technologies and virtual communication, the process of the development of their communication skills becomes more difficult as students have relatively little experience of communication in live conditions, which leads to the fact that they are poorly oriented in situations of real dialogical interaction and it is difficult for them to interpret the communicative behavior of the interlocutor.

The study of the conceptual provisions of the «action learning» methodology, as well as the general theory of training, made it possible to clarify the concept of a foreign language communicative online training. Regarding the process of the development of students' dialogical speech skills in foreign language lessons at a specialized university, foreign language communicative online training is a modern teaching technology aimed at actively developing the skills of dialogical speech in a foreign language in the process of intense intercultural online interaction.

The key features of a foreign language communicative online training, which distinguishes it from other types of communication training are: 1) focus on the integrated development of general communicative, special perceptual and interactive skills of dialogic speech; 2) creation of conditions for active secondary socialization of the individual in a foreign language society; 3 ) usage of a foreign language as the main means of teaching.

The main distinguishing features of the technology of foreign language communicative online training, contributing to an increase in the effectiveness of teaching students a foreign language is: 1) orientation towards the social development of the individual; 2) creating conditions for expanding the communicative experience in a foreign language; 3) creating conditions for the development of foreign language communicative skills of dialogical speech.

\section{Conclusion}

Based on the results of the experimental training, it can be concluded that foreign language communicative online training has a positive impact on the social and communicative development of the personality of bachelor's degree students majoring in 44.03.01 «Pedagogical education» with a minor of «English as a foreign language» at Linguistics University of Nizhny Novgorod, Russia.

By the means of the indicated technology, these students accumulate previously acquired experience of social interaction with the newly acquired one, which contributes not only to the development of social competence, but also to the formation of such significant personality traits as self-awareness and self-esteem, which help to form their own identity.

Thus, a foreign language communicative online training cancover the deficit of live communication observed because of the development of Internet technologies. Itis able to give an impetus to university students to rethink and rework the results of their activities in various 
social groups and communities to form their own individuality and harmonious introduction to the norms and values of the world society.

\section{References}

1. M. Bolognesi, P. Vernillo, How abstract concepts emerge from metaphorical images: The metonymic way. Language \& Communication, 69, 26-41 (2019) https://doi.org/10.1016/j.langcom.2019.05.003.

2. C.P. Campbell, Training Course/Program Evaluation: Principles and Practices. Journal of European Industrial Training, 22(8), 322-344 (2018) https://doi.org/10.1108/03090599810234881.

3. A.H. Eagly, W. Wood, Social Role Theory. Handbook of Theories of Social Psychology, 2, 456-476 (2012)

4. E. Etel, V. Slaughter, Theory of mind and peer cooperation in two play contexts. Journal of Applied Developmental Psychology, 60, 87-95 (2019) https://doi.org/10.1016/j.appdev.2018.11.004

5. M.V. Klarin, Innovation models of education: international experience studies. $1 \mathrm{st}$ edn. (Publishing house Luch, Moscow, 2018)

6. I.M. Kurdyumova, The theory of action learning by R. Revans as a way to improve the educational process. Modern trends in the development of science and technology = Current trends in the development of science and technology, 8, 74-78

7. S. Leher, K.S. See, The impact of foreign language caregiving on native language acquisition. Journal of Experimental Child Psychology, 185, 51-70 (2019) https://doi.org/10.1016/j.jecp.2019.04.010.

8. E. Mayweg-Paus, M. Thiebach, R. Jucks, Let me critically question this! - Insights from a training study on the role of questioning on argumentative discourse. International Journal of Educational Research, 79, 195-210 (2016) https://doi.org/10.1016/j.ijer.2016.05.017.

9. H.T. Min, Effect of teacher modeling and feedback on EFL students' peer review skills in peer review training. Journal of Second Language Writing, 31, 43-57 (2016) https://doi.org/10.1016/j.jslw.2016.01.004.

10. M.N. Norbahira, A.R. Radzuwan, A review of theoretical perspectives on language learning and acquisition. Kasetsart Journal of Social Sciences, 39(1), 161-167 (2018) https://doi.org/10.1016/j.kjss.2017.12.012.

11. G.K. Selevko, Modern educational technology.1 edn. (Publishing house Narodnoe obrazovanie, Moscow, 2018)

12. R. Shields, The sustainability of international higher education: student mobility and global climate change. Journal of Cleaner Production, 217, 549-602 (2019). https://doi.org/10.1016/j.jclepro.2019.01.291.

13. G.V. Sorokoumova, The Possibilities of psychological training in the prevention and overcoming of communicative barriers by the students while studying foreign languages. Humanisation of education, 4, 114-123 (2018)

14. M. Wenzel, M. Will, The communicative constitution of academic fields in the digital age: The case of CSR. Technological Forecasting and Social Change, 146, 517-533 (2019) https://doi.org/10.1016/j.techfore.2019.05.006. 
15. C. Wrigley, G. Mosely, M. Tomitsch, Design Thinking Education: A Comparison of Massive Open Online Courses. She Ji: The Journal of Design, Economics, and Innovation, 4(3), 275-292 (2018) https://doi.org/10.1016/j.sheji.2018.06.002. 